\title{
As dimensões morais de classe social: Avaliações do mercado de trabalho e das experiências de vida de recém-diplomados em Direito
}

Ricardo Bernardes Pereira ${ }^{1}$

Resumo: Este artigo investiga as avaliações do mercado de trabalho e das experiências de vida de recém-diplomados em Direito de origem nas classes populares, examinando as relações entre a moralidade, definida enquanto avaliação e valorização, e desigualdade de classe. Classe social, além de ser um sistema de classificação, também é uma escala de julgamento em que ocupações e experiências de vida são avaliados. Com base na classificação ocupacional, nas definições de boa vida e na comparação com as experiências de vida dos pais, este artigo mostra as principais fontes de respeito do grupo estudado.

Palavras-chave: classe social; Direito; moral; desigualdade; mercado de trabalho

The moral dimensions of social class: Labor market and life experience evaluations of newly-graduates of Law

Abstract: This article investigates the labor market and life experience evaluations of newly-graduates of Law from working-class families, examining the relations between morality, defined as evaluation and valuation, and class inequality. Social class is a system of classification and a scale of judgement in which occupations and life experiences are evaluated. Drawing on occupational classification,

1 Programa de Pós-Graduação em Sociologia/ Universidade Federal do Rio Grande do Sul (UFRGS) - Rio Grande do Sul - Brasil - ricardocsociais@gmail.com 
definitions of good life and comparison with parents' life experiences, this article shows the main sources of respect of the group analyzed.

Keywords: social class; Law, moral, inequality, labor market.

\section{Introdução}

O crescimento do ensino superior acarreta o aumento do número de credenciados e licenciados a exercer diversas ocupações de alto status socioeconômico. À medida que novos credenciados ingressam no mercado de trabalho, uma parcela é absorvida nas ocupações de formação, especialmente nas áreas em que a geração de empregos é relativamente flexível. A maior competição no mercado de trabalho tende a limitar o crescimento salarial ou a reduzir o salário médio das ocupações (Elias; Purcell, 2004). Uma parcela significativa dos novos diplomados passa a trabalhar em ocupações que não demandam as competências adquiridas no ensino superior, sendo chamados de sobrequalificados (Mehta et al., 2011; Figueiredo et al., 2017). Empregos ocupados em um momento no passado por pessoas sem ensino superior passam a ser majoritariamente ocupados por pessoas com esse perfil (Collins, 1979; Tholen, 2017a).

Os membros das classes populares que concluem o ensino superior, diferentemente dos seus pais, têm uma credencial que possibilita, mas não garante, necessariamente, a ascensão social, uma vez que a inserção dos diplomados em um mercado de trabalho com inflação de diplomas pode implicar inserção ocupacional dos filhos em condições parecidas com a dos seus pais sem ensino superior.

Este artigo investiga as avaliações das ocupações e das experiências de vida pelos bacharéis em Direito recém-diplomados de origem social nas classes populares. O objetivo central é examinar as relações entre a moralidade (compreendida enquanto avaliação e valorização) dos bacharéis em Direito recém-diplomados e a desigualdade de classe no Brasil. O aumento da escolaridade tem consequências sobre os valores e expectativas de vida (Baker, 2014). Espera-se que as definições de boa vida dos membros das classes populares com ensino superior completo sejam próximas do estilo de vida valorizado pelas classes médias.

A literatura sociológica mundial tem se ocupado em compreender a moralidade e as fontes de respeito e reconhecimento das classes sociais inferiores. Em pesquisa realizada nos Estados Unidos e na França, Lamont (2000) examinou como homens de classe trabalhadora estabelecem fronteiras morais com administradores e profissionais de ensino superior, imigrantes e pessoas de outras 
"raças". Na perspectiva do grupo pesquisado, a classe média carece de integridade pessoal e sinceridade. Incapazes de corresponder às definições de valor pessoal das classes dominantes, centradas no ganho material e na posição ocupacional, os homens da classe trabalhadora elaboram fontes alternativas de valor pessoal. Por exemplo, nos Estados Unidos, os trabalhadores valorizam a integridade moral, comprometimentos familiares e uma ética de trabalho protestante. Na França, por outro lado, os trabalhadores demonstraram preocupar-se com questões de igualdade social e solidariedade, em detrimento de uma visão de mundo voltada à responsabilidade individual e à ética do trabalho, como os trabalhadores norte-americanos. Sennett e Cobb (1972) afirmam que a incapacidade de os trabalhadores norte-americanos corresponderem ao esquema dominante da sociedade de definir valor pessoal em termos de posição social, realizações individuais e ganho material gera feridas de classe. Embora os trabalhadores norte-americanos busquem formas alternativas de respeito, por meio das relações familiares e definições de bom caráter, as definições dominantes são internalizadas. Stuber (2006), em uma pesquisa com estudantes universitários das classes trabalhadoras de uma universidade de elite nos Estados Unidos, mostra que os estudantes das classes trabalhadoras percebem os seus pares das classes altas como preocupados com questões consideradas "irrelevantes" - aparência, consumo de bens materiais e popularidade -, considerando-os preguiçosos e ostentadores. Embora a cultura da classe alta seja negativamente avaliada, os estudantes afirmaram que gostariam de ter as mesmas condições de vida dos seus pares ricos.

Este artigo apropria dessa literatura para mostrar como bacharéis de Direito recém-diplomados das classes populares classificam as ocupações, definem boa vida e bom trabalho e comparam as suas experiências de vida com a de seus pais, relacionando esses esquemas culturais a dimensões subjetivas da desigualdade. O campo do Direito oferece um caso apropriado para compreender essas relações pelo alto nível de desigualdade intraocupacional. No topo das ocupações do campo do Direito, as carreiras jurídicas (juiz, promotor, delegado, defensor público, procurador de justiça, desembargador, dentre outras) geralmente oferecem salários do grupo um por cento mais rico (Medeiros, 2015), mas o ingresso nelas é altamente competitivo. A remuneração dos sócios de escritórios de advocacia também é relativamente alta, apesar de haver uma variação salarial maior em comparação às carreiras jurídicas do setor público. Por outro lado, muitos bacharéis enfrentam um mercado competitivo e relativamente saturado, não conseguindo se inserir nas ocupações jurídicas e com uma renda não muito superior a um ou dois salários mínimos. 
Os dados da pesquisa são relevantes para compreender a natureza da desigualdade social brasileira. $\mathrm{O}$ grupo estudado usa como referência as possibilidades de condições de vida disponíveis na sociedade para realizar os projetos de vida e avaliar as condições atuais. O pequeno conjunto de ocupações positivamente avaliadas e a elevada diferença percebida entre esse conjunto e o restante das ocupações possíveis de serem alcançadas pelos entrevistados levam a uma competição cruel pelos postos de trabalho no setor público, a uma insatisfação com as condições atuais e a uma expectativa de somente conquistar a realização pessoal no futuro. Embora uma parcela significativa dos recém-diplomados tenha conseguido a inserção profissional na área de formação, conseguiram-na nas ocupações mais negativamente avaliadas do campo do Direito, como associados de escritórios particulares. O grupo estudado usa as ocupações do setor público como referência para a avaliação do salário, das condições de trabalho e dos benefícios empregatícios da ocupação atual. Ao mesmo tempo, tendem a avaliar a sua posição social de modo superior à posição de seus pais.

\section{Moralidade, Relações de Classe e Desigualdade}

O processo de avaliação, a atribuição moral e a autoridade de atribuir valor a bens sociais são centrais para compreender relações de classe e desigualdade social (Skeggs, 2005). Classe social pode ser tratada como um sistema de classificação no qual ocupações, escolhas de vida e tudo o mais são postos em uma escala de julgamento (Skeggs, 2004). Avaliações morais são relevantes, pois são base de estratégias de ação (as pessoas tomam ações para tornarem-se a pessoa que consideram desejável), afetam a satisfação pessoal, a percepção de sucesso e o sentimento de injustiça, e geram normas sobre como a pessoa deve tratar os outros e como deve ser tratada (Sayer, 2005a, 2005b).

Uma sociedade de sucesso é aquela que provê aos seus membros os recursos para viver uma vida segura, saudável e significativa (Lamont; Hall, 2013). Possibilita formas de respeito a um conjunto amplo da sociedade (Evans, 2013). Darwall (1977) distingue dois tipos de respeito pela capacidade de provisão pela sociedade: respeito por reconhecimento e respeito por apreciação. $\mathrm{O}$ respeito por reconhecimento é o tratamento apropriado na deliberação de uma pessoa sobre uma característica em questão do objeto. Refere-se a uma ação apropriada no que concerne à lei, ao corpo humano, à instituição social, às coisas e aos seres não humanos. Com relação a pessoas, o respeito por reconhecimento significa atribuir uma consideração adequada ao fato de ser humano, considerando as características adscritas, as necessidades vitais e os sentimentos. $\mathrm{O}$ respeito 
por apreciação (no original em inglês, appraisal respect), por outro lado, é uma atitude de apreciação positiva de uma pessoa ou de seus méritos, manifesta por meio da excelência de caráter. Caráter, segundo Darwall (1977), são disposições duráveis no longo prazo. $\mathrm{O}$ respeito por apreciação leva em consideração aspectos "morais" (exemplos: honestidade, lealdade e prudência) e a competência e habilidade na execução de tarefas. Diferentemente do respeito por reconhecimento, que é possível de ser atribuído a todos, o respeito por apreciação é um bem escasso, pois é comparativo, sendo atribuído a pessoas com características acima da média. Sennett e Cobb (1972) e Sennett (2004) analisam essa forma de respeito ao tratar das desigualdades de classe social. Como existem bases de respeito compartilhadas, em certa medida, por todos os membros e o alcance das bases de respeito é limitado, as desigualdades são intrínsecas em sociedades capitalistas e permanecem sendo significativas para o bem-estar, mesmo quando o padrão de vida da população supera o nível de atender às necessidades básicas. Para lidar com essas desigualdades, os atores sociais podem responder definindo um padrão de desempenho suficientemente bom. Também podem compensar as deficiências em certas áreas, desvalorizando-as e investindo os seus recursos em áreas em que podem florescer (Sayer, 2005a).

Muitos autores da literatura internacional têm tratado o neoliberalismo como fonte de definições dominantes de respeito por apreciação (Lamont; Hall, 2013; Ball, 2016; Satybaldieva, 2018; Francombe-Webb; Silk, 2016; McKenzie, 2016). Segundo essa literatura, o capitalismo contemporâneo é caracterizado por instituições e por um imaginário social que definem respeito em termos de consumo, posição no mercado de trabalho e qualificação. Os atores sociais de todas as classes sociais são levados, a fim de adquirirem respeito por apreciação, a investir constantemente em si mesmos. Os membros das elites e das classes médias são mais propensos a incorporar a subjetividade requerida pelo neoliberalismo.

Embora haja definições dominantes de respeito, os grupos sociais são capazes de responder elaborando outras moralidades, as quais assumem uma posição subordinada. Lamont (2012) elabora o conceito de heterarquia para se referir à existência de múltiplos sistemas de valorização e avaliação. Ela afirma que as classes populares adotam um self de cuidado, preocupadas com o caráter e com as relações familiares, como uma estratégia de resiliência (Lamont, 2000). A literatura também mostra a existência de um self piedoso entre as classes populares, centrado na religião (Souza, 2009; Skeggs, 2014; Satybaldieva, 2018). No entanto, as heterarquias estão sujeitas a processos de subordinação às culturas dominantes. A cultura valorizada pelas instituições sociais dominantes 
e considerada, em alguma medida, valorizável por todos os membros da sociedade é a cultura das classes dominantes (Skeggs, 1997; 2005; 2014). Além disso, a marginalização das culturas das classes populares e a valorização da cultura das classes médias e das elites são mecanismos de reprodução social (Bourdieu, 2007; Ridgeway, 2014; Skeggs, 1997; 2005).

As estruturas do mercado de trabalho brasileiro dificultam o acesso a formas de respeito a amplos setores da sociedade, pois oferecem condições de vida muito diferentes a pessoas situadas em posições sociais distintas. Existe uma segmentação no mercado de trabalho entre setor público, setor privado formal e setor privado informal. Estar situado em cada um desses setores implica ter salários, estabilidade no emprego, aposentadoria, acesso a crédito, benefícios (vale-alimentação, seguro desemprego, auxílio creche, FGTS e acesso a crédito) muito desiguais. Outra forma de desigualdade são as diferenças salariais pela escolarização. Os profissionais com ensino superior possuem uma renda, em média, 135\% maior do que quem possui ensino médio, uma das mais díspares do mundo (OECD, 2016: 114). Dentro de um grupo ocupacional também há uma grande variação salarial (Medeiros, 2005). No Direito, por exemplo, os salários variam de em torno de mil e quinhentos reais a associados (contratados sem carteira assinada) de pouca experiência em escritórios privados, passando por salários na faixa de 20 mil reais nas carreiras públicas até salários astronômicos de sócios de grandes bancas.

Pesquisas brasileiras com recém-formados têm enfatizado as dificuldades iniciais de inserção no mercado de trabalho e as consequências psicológicas dessa experiência (Lima; Gomes, 2011), a posição inicial no mercado de trabalho (Maciante et al., 2015; Lemos, Dubeaux; Pinto, 2009) e as estratégias de obtenção de emprego (Silva, 2010). Pesquisas com graduandos das classes populares são mais numerosas. Os valores dos graduandos são um tema recorrente e, de modo geral, as pesquisas mostram um desejo de ascensão social, valorização do ensino superior, desvalorização das ocupações que não requerem ensino superior, valorização da família, sentimentos positivos dos pais pelo ingresso dos filhos no ensino superior e valorização das oportunidades abertas pelo diploma universitário (Castro, 2014; Mongim, 2016; Casali; Mattos, 2015; Oliveira; Bock, 2016; Neves, Faro; Schmitz, 2016). Essas pesquisas mostram a internalização dos valores dominantes de consumo, posição no mercado de trabalho e qualificação. Os resultados sobre os graduandos e recém-egressos de origem nas classes populares são distintos dos observados nas pesquisas com adultos e idosos de baixa escolaridade (Souza, 2009; Souza, 2012) e de jovens em outros contextos (Willis, 1991), nas quais a presença de heterarquias é mais marcante. 


\section{Procedimentos metodológicos}

A fim de compreender as percepções sobre o mercado de trabalho de recém-egressos das classes populares, optou-se por delimitar um campo específico. O curso de Direito foi escolhido por ser um dos cursos com o maior número de egressos (IBGE, 2017), ter um alunado diversificado em termos de nível socioeconômico (Simonsen; Gonzalez, 2014; Simonsen; Gonzalez, 2016), ser um campo caracterizado por fechamento ocupacional (Flemmen et al., 2017; Ruggera; Barone, 2017) e possibilitar o ingresso em ocupações de alta remuneração. A escolha por um campo com fechamento ocupacional deveu-se à intenção de compreender as percepções daqueles que estão situados fora do campo ocupacional, apesar de ter a licença para atuar em uma área que possui uma definição relativamente clara de ocupação jurídica.

O sintagma classe social foi definido com base em três critérios: ocupação, escolaridade dos pais e renda. A literatura internacional da área de estratificação social ainda não chegou a um consenso mínimo a respeito da operacionalização do conceito de classe social em pesquisas qualitativas (Bottero, 2012). Lidar com a ambivalência na classificação dos entrevistados é um problema recorrente entre pesquisadores da área, pois existem pelo menos 14 critérios para operacionalizar conceitos mais abstratos, como capital cultural e capital econômico (Payne; Grew, 2005).

Foram entrevistados 33 bacharéis em Direito recém-formados residentes na capital e região metropolitana de um estado no sul do país. Além disso, foram realizadas observações dos participantes em dias de concurso público, provas da $\mathrm{OAB}$ e feiras de oportunidades. Classe popular foi definido como não ter pais com ensino superior. Do total de entrevistados, três são filhos de agricultores; sete são filhos da classe urbana precária²; sete são filhos de operários; sete são das ocupações intermediárias ${ }^{4}$; quatro estão situados entre as classes médias e as classes intermediárias ${ }^{5}$ e cinco são claramente de classe média ${ }^{6}$.

2 Classe urbana precária: empregada doméstica, merendeira, vigilante, vendedor informal autônomo, vendedor em loja, serviços gerais em empresas, caixa de supermercado, vigia, revendedora de cosméticos, trabalhador autônomo. Metalúrgico (4); Eletricista (1); mestre de obras (1); motorista de grande empresa (1).

4 Classe intermediária refere-se aos trabalhadores entre as classes precárias e as classes médias. Servidor público de baixo escalão, militar de baixa patente, microempresários, professora de primário, taxista.

5 Uma ou duas das características para definir classe média está presente: pai não tem ensino superior e trabalha no setor público recebendo alto salário (2); pai não tem ensino superior, atua em ocupação profissional e tem salário relativamente alto (1); pai faleceu quando o entrevistado era recém-nascido, mãe trabalha em ocupação precária e os avós de ambos os lados têm ensino superior completo e contribuíram para a educação do entrevistado (1).

6 Pais com ensino superior completo, ocupação profissional e renda relativamente alta. Classe média é usado no sentido de uma classe com alto capital cultural sem a posse dos meios de produção. 
Os entrevistados de classe média de origem foram selecionados para compor um grupo de controle.

O método de seleção de participantes foi a "bola de neve". A amostra foi composta por $60 \%$ de pessoas do sexo masculino. As idades variaram de 24 a 45 anos, sendo a idade média 27,9 anos. Dezessete entrevistados foram contemplados com bolsa de estudos (PROUNI ou bolsa da própria instituição), quatro financiaram os estudos pelo Fies ou crédito educativo privado, quatro estudaram em universidades públicas e oito bancaram a universidade com os próprios recursos. Vinte e um entrevistados formaram-se em universidades confessionais, cinco estudaram em instituições de ensino superior com fins lucrativos, quatro em uma universidade pública federal e dois formaram-se em uma universidade comunitária. Diferentemente de outras regiões do país, a maioria dos egressos do curso de Direito na cidade da pesquisa não é formada em universidades com fins lucrativos. 0 tempo médio de formado foi de 3,4 semestres.

O fato de, em média, terem concluído a graduação há menos de dois anos não significa que os entrevistados têm somente dois anos de experiência no mercado de trabalho. A idade é um indicador mais adequado do que o tempo de formação no ensino superior para captar o tempo de experiência no mercado de trabalho. Para os propósitos da pesquisa, as experiências em empregos antes e durante a graduação e os estágios são tão relevantes quanto os empregos depois da graduação, pois as avaliações dos empregos são, em parte, resultado do conjunto de experiências vivenciadas em todos esses momentos.

As entrevistas tiveram duração média de uma hora e meia. Aconteceram entre setembro de 2017 e abril de 2018. Estas foram divididas em duas partes. Na primeira, o entrevistado narrava as experiências no mercado de trabalho e nas instituições educacionais entre o fim do ensino médio e a entrada no ensino superior, durante a graduação e depois da graduação. Na segunda parte, foi aplicado o método de identificação de fronteiras simbólicas (Lamont; Molnár, 2002; Lamont, 2000). Pedi para os entrevistados avaliarem suas experiências de vida em comparação com os familiares, colegas de classe média de origem e profissionais em diferentes posições no mercado de trabalho jurídico.

\section{As experiências dos bacharéis em Direito recém-formados no mercado de trabalho}

Nas últimas décadas, o número de registros em todas as ocupações reguladas e certificadas, como advogado, dentista, médico e arquiteto, tem aumentado. No campo do Direito, por exemplo, havia 183 mil advogados registrados na OAB em 1980 (OAB, 1981 apud Arruda Júnior, 1983) em uma população de 119 
milhões de pessoas. Em 2018, o Brasil tinha 1 milhão e 160 mil advogados registrados na mesma entidade em uma população de 209 milhões.

Dados nacionais de pesquisa do Sindicato das Entidades Mantenedoras de Ensino Superior no Estado de São Paulo (SEMESP) de egressos do curso de Direito de todas as classes sociais com até dois anos de formação mostram que $56,3 \%$ trabalham na área de formação, 11,3\% estão ocupados em outras áreas e 23,4\% estão desempregados, preparando-se para concursos, em um curso de segunda graduação ou na pós-graduação. De acordo com essa pesquisa, 56,3\% dos inseridos no mercado de trabalho recebem até 3 mil reais mensais. Dentre as três grandes áreas analisadas (Direito, Engenharia e Administração), os bacharéis em Direito estão em maior proporção atuando na área de formação ${ }^{7}$ (Semesp, 2017; A Tribuna, 2017).

Os dados da pesquisa que resulta neste artigo mostram uma inserção parecida no mercado de trabalho. Dentre os 33 entrevistados, 16 (48,5\%) atuam na área do Direito, cinco atuam em outras áreas (15,2\%) e 12 (36,4\%) estão desempregados, em segunda graduação, preparando-se para concursos ou em cursos de pós-graduação. Dois entrevistados recebem acima de dez mil reais mensais, quatro recebem entre 2,5 e 5 mil reais, quinze recebem entre 1,5 e 2,5 mil reais e doze não têm renda fixa.

A maioria dos empregados em escritórios tem contrato de associado, o que significa principalmente não ter acesso aos benefícios da CLT. Essa prática foi observada em escritórios de diferentes tipos, sejam eles pequenos, médios ou grandes. Com esse contrato, as regras de número de horas semanais trabalhadas, de pagamento das horas extras e dias de férias são sujeitas a um acordo entre as partes. São comuns relatos nos quais o número de horas ultrapassa 40 horas semanais. Não ter o contrato de CLT afeta o projeto daqueles que planejam comprar veículos automotores ou imóveis, pois adquirir crédito é mais difícil quando não há comprovação de renda por contrato com carteira de trabalho assinada. Quando perdem o emprego, não têm acesso ao FGTS e ao seguro desempregado. O salário dos contratados em escritório com dois anos de experiência, na maioria das vezes, gira em torno de dois mil reais.

Uma alternativa ao emprego de escritório é a atuação por conta própria. Montar um escritório exige investimento inicial. Alugar, reformar e mobiliar uma sala são custos considerados altos por muitos entrevistados. Como o

7 Apesar de os dados da Semesp serem de uma pesquisa de mercado encomendada por um órgão representante de instituições de ensino superior, elas foram citadas no artigo por seremos únicos dados encontrados sobre o grupo pesquisado. 
recebimento dos honorários leva um tempo significativo para ser efetivado depois de iniciado o processo judicial, é necessária uma fonte de recursos extra para lidar com meses sem entrada de dinheiro. Soma-se a isso as dificuldades de captação de clientes. Muitos recém-graduados das classes populares não têm os recursos necessários para a abertura de escritório e optam por atender os clientes no prédio da $\mathrm{OAB}$, na própria casa ou em bibliotecas e cafeterias. Os clientes atendidos dessa forma geralmente são pessoas conhecidas ou amigos de pessoas conhecidas. A renda recebida mensalmente é baixa. Muitos definem esse tipo de trabalho autônomo como um "bico".

A atuação em áreas fora do mercado de trabalho jurídico geralmente está associada às experiências no curso de Direito ou às experiências escolares ou laborais pregressas. As ocupações observadas foram: agente administrativo (2 entrevistados), analista em função de ensino superior, motorista de ônibus e técnica em eletrônica. Os salários dos entrevistados nas três últimas ocupações são maiores do que o dos entrevistados atuando em escritórios e, além disso, possuem mais benefícios, enquanto o salário dos agentes administrativos é semelhante ao dos empregados em escritórios. A literatura sobre o mercado de trabalho dos graduados em contextos de massificação do ensino superior mostra que os bacharéis tendem a ocupar profissões técnicas ou de escritório relacionadas à área de formação no ensino superior (Stasio, 2017; Tholen, 2017c). Esse fenômeno tem sido observado no campo do Direito. Os dados mostram uma procura elevada pelos cargos de agente administrativo nas instituições do sistema de justiça. Embora somente uma entrevistada atue nesses cargos, muitos demonstraram o interesse e prestam os concursos públicos de agente administrativo.

As elites do mercado de trabalho em Direito são as carreiras jurídicas do setor público, a posição de sócio de escritório e o emprego em escritório de atuação internacional. Nesses cargos, o salário ultrapassa o valor de dez mil reais mensais. Os concursos das carreiras públicas requerem experiência em ocupações jurídicas. A aprovação para os concursos mais concorridos demora anos e exige investimento em dinheiro. Atualmente, por exemplo, os magistrados ingressam na carreira, em média, em torno de 33 anos de idade (CNJ, 2013: 33). Nas observações de participantes em dias de concurso, notei que a faixa etária predominante é entre 30-40 anos e muitos candidatos vieram de outros estados para disputar o concurso da magistratura e da procuradoria de justiça. Em evento público com sócios de grandes bancas de advocacia, foi afirmado que o perfil desejado é de quem possui experiência internacional e proficiência em línguas estrangeiras, tem relações (isto é, conhece empresários), conhecimentos 
de negócios, habilidade para interagir com empresários e diretores de grandes empresas e espírito corporativo, demonstra firmeza na fala, habilidade de negociação e conhecimentos sobre a cultura da classe corporativa. O ingresso tanto nas carreiras jurídicas do setor público quanto nos escritórios empresariais é difícil para quem é de origem nas classes populares. A posição de sócio de um escritório bem-sucedido ainda não é viável a quem é recém-formado e, por isso, essa carreira não foi analisada. Os escritórios de renome internacional não fazem parte do mapa mental dos recém-formados das classes populares. Muitos entrevistados desconhecem esse mercado. No entanto, ter uma carreira jurídica no setor público é uma aspiração de muitos.

\section{Classificação ocupacional segundo os entrevistados}

Os entrevistados analisam as possibilidades, elaboram estratégias de inserção profissional e avaliam as ocupações de acordo com os seus recursos e experiências prévias. Avaliar ocupações fora de suas possibilidades não demonstrou ser saliente nas falas. Antes de ingressar na universidade, muitos entrevistados trabalharam em ocupações de nível médio. A maioria saiu desses empregos para fazer estágios durante toda a graduação. Nos estágios em escritórios privados e órgãos públicos, adquiriram conhecimento sobre as condições de vida dos trabalhadores nesses setores.

No mapa mental dos entrevistados, as ocupações do setor público e a docência universitária estão no topo da hierarquia. A docência universitária é valorizada principalmente pelas características de ensinar conhecimentos jurídicos e doutrinar politicamente as novas gerações. O emprego em escritório de advocacia situa-se consideravelmente abaixo. Estar em posição subordinada, receber um salário considerado "baixo", não ter alguns benefícios trabalhistas e realizar atividades de alto nível de estresse são justificativas para a relativa desvalorização dessa ocupação. Na posição inferior, estão as ocupações do setor privado que não exigem ensino superior. Os empregos de atendente de telemarketing, vendedor no comércio e secretária são exemplos de ocupações exercidas em algum momento da vida por muitos entrevistados. Considere como Atanásio classifica as ocupações:

Atualmente, pra vida que eu estou vivendo nesse momento, pra mim, seria ideal uma carreira pública. Ahn, claro, pensando em iniciar uma carreira pública, no sentido de ser servidor e, talvez, pra frente, fazer um concurso para ser membro de algum órgão do judicário, ser juiz, ser promotor, sei lá. Isso é possível. O preparo (para as carreiras do judiciário) é horrível. A preparação 
é horrorosa. As pessoas que passam, em geral, são pessoas que têm como passar cinco anos só estudando, o que não é o meu caso. Então, se eu parar pra estudar cinco anos, eu morro de fome. Agora, pra um concurso de servidor, talvez eu consiga. É com isso que eu estou contando num futuro menos remoto, digamos assim, mais próximo, de médio prazo, digamos. (...) Sempre tive uma certa queda, assim, com a coisa da academia. De poder trabalhar em sala de aula. Eu gosto da ideia de ser professor em sala de aula. Nem tanto da ideia da pesquisa e tudo mais. Mais a coisa da relação com o aluno. $\mathrm{Eu}$ acho um ambiente extremamente rico. Isso é o que mais me encanta na ideia de fazer mestrado e ser professor. (...) Mesmo a advocacia, que talvez fosse a última dessa lista, às vezes eu me acordo pensando, assim, como seria bom ter uma certa autonomia. Poder acordar agora e eu poder fazer o meu trabalho, sem ter que obedecer a ninguém. Claro, tem isso e tem em ser um advogado trabalhando no escritório de alguém, que é ser empregado. Embora os caras não assinem a tua carteira, e te chamem de sócio, eles te tratam como um empregado. Pra mim, essa certamente seria a pior das opções. É algo que efetivamente eu não gostaria de tá fazendo. Isso seria ganhar um salário muito baixo. Muito baixo, não, mas, tipo, sei lá, gente sai da faculdade ali sai ganhando mil reais, mil e duzentos reais pra trabalhar dez horas por dia e fazer audiência no interior. Não te dão nenhuma realização ainda por cima. É só obedecer e cumprir a tarefa do escritório. Eu como nunca tive um sonho de construir carreira na advocacia, acho detestável essa ideia.

Atanásio, 24 anos, em cargo comissionado no setor público

As ocupações do setor público são bem avaliadas por oferecerem um bom salário, estabilidade, benefícios, menos estresse do que no escritório e respeito público. Mesmo as ocupações de agente e técnico, que requerem somente o ensino médio completo, são preferíveis ao trabalho no escritório. O objetivo final da maioria dos entrevistados é ingressar nas principais carreiras públicas do sistema de justiça. Como muitos percebem que a preparação para esses concursos requer tempo e recursos econômicos, os quais a maioria não possui, eles utilizam uma estratégia de ser aprovado nos concursos menos disputados e, paulatinamente, ascender nos cargos públicos. Essa estratégia é chamada de "escadinha" pelos entrevistados. Por exemplo, Virgínio trabalha em um escritório de advocacia há seis anos. Afirma receber 2.200 reais mensais. $O$ sonho dele é tornar-se delegado. Como ainda não se sente preparado para ser aprovado nesse concurso e a falta de recursos financeiros limita-o a disputar somente as vagas no estado onde reside, ele tem se preparado para vários concursos tanto 
de nível médio quanto superior. Tem mais confiança em ser aprovado no concurso do corpo de bombeiros, que requer nível médio.

Eu ganho, no escritório, 2200 reais. Nos bombeiros, eu vou ganhar 3800 reais; é uma boa diferença. O escritório te toma muito tempo e a tua cabeça também. Tu sai do escritório, tu tá indo pra casa, tu tá pensando em processo. Tu tá em casa, tu sonha com processo, entendeu? Tu tá montando o que eu vou escrever amanhã naquele prazo que eu tenho que fazer, naquela contestação, naquele recurso. O bombeiro, eu tenho colegas que se formaram comigo. Antes até de fazer o concurso, eu conversei com eles, eles disseram que o bombeiro é bom por isso, porque tu vai ganhar um valor legal. A tua cabeça vai tá mais tranquila porque é um trabalho mais físico, digamos. Tem que pensar, mas não é um trabalho que tu vai passar o dia inteiro usando a tua cabeça, que nem no direito. Então, fica mais dentro do batalhão.

Virgínio, 25 anos, advogado associado

Trabalhar no setor público em ocupações de nível médio é preferível a trabalhar como advogado associado pelos salários altos do setor público, pelo menor nível de pressão, pela estabilidade e maiores benefícios. Embora a maioria dos entrevistados valorize trabalhar em ocupações jurídicas, eles abririam mão das delas a fim de ter as vantagens do setor público.

Ascender socialmente, estar no topo das carreiras jurídicas e receber um salário alto estão no centro das estratégias de vida dos entrevistados. Há poucos relatos de heterarquias. $\mathrm{O}$ ativismo político, por exemplo, apareceu nas falas de forma subsumida ao valor central de ascensão social. Catarina afirma desejar relacionar o ativismo político com a carreira de defensora pública, que, no estado da pesquisa, recebe aproximadamente 20 mil reais.

Eu pretendo seguir na advocacia por um tempo, mas o meu objetivo sempre foi prestar concurso público pra defensoria. Até por essa questão que tava te falando de gostar de ter uma função social, de poder, enfim, auxiliar as pessoas que tão nessa situação de criminalidade. O que a defensoria te oferece? A defensoria te oferece todo o suporte da instituição, né?, do estado e é uma excelente remuneração. Então, o que acontece? Eu gosto muito de advogar pra pessoas em situação de hipossuficiência. Eu faço muitos casos pro bono, que é quando você não cobra honorários. Mas isso não me mantém, né? Eu também tenho as minhas contas pra pagar. A defensoria, eu vejo que tu consegue conciliar as duas coisas, né? Tu vai tá exercendo esse tipo de advocacia pública, mas tu vai ter a tua remuneração garantida todo mês.

Catarina, 24 anos, advogada autônoma 
O trabalho na advocacia é negativamente avaliado, principalmente, por ter as carreiras públicas como a maior referência. Os entrevistados narravam por um longo tempo sobre as características negativas do trabalho em escritório, os concursos para os quais estão em preparação e as carreiras que sonham em alcançar. Quando eram motivados a comparar o trabalho no escritório com os empregos exercidos antes de ingressar na universidade ou com as ocupações de seus pais, quando estes tinham ocupações "precárias", o trabalho no escritório era mais positivamente avaliado. Por exemplo, Rui trabalhou por quatro anos como atendente de telemarketing, recebendo um salário mínimo em um regime de seis horas, antes de ingressar no curso de Direito. Afirma que o emprego era altamente estressante. Segundo narra, apenas permaneceu por esse período para poupar dinheiro para cursar Direito, caso demorasse para conquistar uma bolsa de PROUNI. Comparando o emprego atual com o de atendente de telemarketing, ele afirma que, como advogado associado, o salário é melhor e o nível de estresse é menor. A ausência de benefícios da ocupação atual não é levada em consideração. No entanto, Rui não quer permanecer como advogado associado por muitos anos, pois, a curto prazo, almeja conquistar a posição de técnico ou analista no Tribunal de Justiça e, a longo prazo, ser juiz. A falta de estabilidade, o baixo salário e os poucos benefícios surgem como critérios relevantes para avaliar a experiência atual no emprego somente na comparação com as últimas ocupações.

Os empregos sem exigência de ensino superior do setor privado, apesar de já terem sido exercidos, são pouco utilizados como referência de avaliação das experiências de trabalho. A principal referência são os empregos públicos, os quais oferecem, na percepção dos entrevistados, condições de emprego consideravelmente superiores. Nesse sentido, a preparação para os concursos públicos está presente na maioria das narrativas. De modo geral, o elevado número de bacharéis em Direito tem buscado as poucas vagas disponíveis no setor público devido às desigualdades no mercado de trabalho.

A desigualdade social brasileira em combinação com a internalização dos valores centrais da subjetividade neoliberal tem efeitos negativos sobre as experiências dos entrevistados. Existe uma disparidade enorme entre o salário recebido atualmente e o que poderão ganhar nas principais ocupações do setor público. Na percepção deles, caso continuem no setor privado, o salário irá aumentar no futuro, mas nunca atingirá o patamar do setor público. Consideram, além disso, que os níveis de estresse e de pressão são sempre maiores no setor privado. Estabilidade profissional e muitos benefícios estão ausentes no setor privado. Essas condições geram uma corrida pelos concursos públicos na qual poucos sairão 
vencedores. Adquirir respeito por apreciação é escasso em qualquer sociedade, principalmente em uma na qual as condições de trabalho são díspares.

\section{Definições de boa vida}

Como classe social afeta os relacionamentos, as experiências e as práticas, compreender quais bens são valorizados pelas classes inferiores permite entender a capacidade de atingir bem-estar. Nas definições sobre como viver, alguns podem desejar principalmente os bens monopolizados pelas classes dominantes, enquanto outros podem se preocupar com tipos diferentes de bens. Desigualdade de classe envolve não somente diferenças em riqueza, salário e segurança econômica, como também diferenças no acesso a circunstâncias valorizadas, nos modos de vida e no reconhecimento dos bens sociais e de seus possuidores. As desigualdades importam mais quando impactam a vida que os atores sociais buscam levar, as coisas, relacionamentos e práticas que valorizam (Sayer, 2005a).

Na percepção dos entrevistados, uma boa vida requer condições econômicas favoráveis, bons relacionamentos interpessoais, tempo livre, trabalho com rotina agradável, viagens, estrutura de vida que possibilita realizar os projetos pessoais e formação de família. Os hobbies são passar tempo com os amigos, namorado(a) e família, navegar na internet, assistir a filmes e séries, ler livros, praticar exercícios físicos, viajar e estar na praia ou em meio à natureza.

Ter conforto é central na definição de condições econômicas favoráveis. Morar perto do trabalho ou nas regiões centrais da cidade, passar pouco tempo no deslocamento da casa para o trabalho, realizar atividades de lazer, como comer fora de casa, ir ao cinema, a bares e a cafeterias, ter uma casa limpa e com móveis e eletrodomésticos novos, possuir carro, viajar nas férias dentro do Brasil ou no exterior, fazer compras no supermercado sem se preocupar com o preço final dos produtos, contratar plano de saúde e investir na educação dos filhos constituem a definição de vida confortável.

Os entrevistados diferenciam o consumo que visa ao conforto, considerado legítimo, e o consumo de ostentação, objeto de reprovação. O consumo de ostentação tem por objetivo demonstrar superioridade. Simboliza uma busca ilegítima por bem-estar. Está associado, principalmente, ao comportamento dos seus colegas de graduação das classes superiores. Possuir roupas, carros

8 A literatura sobre buen vivir, a abordagem das capacidades inaugurada por Amartya Sem (2000), as pesquisas sobre felicidade e bem-estar e os modelos convencionais da Economia enriquecem a compreensão sobre os dados empíricos deste artigo sobre a definição de boa vida, mas não puderam ser sintetizados pelo recorte, focalizado no debate sobre classe social, e por limitações de espaço. 
e celulares de marca, frequentar espaços exclusivos somente a quem tem alto poder aquisitivo e viajar constantemente ao exterior ou no Brasil exemplificam formas de consumo inadequadas.

A fim de custear o padrão de conforto necessário para levar uma boa vida, a maioria dos entrevistados define um bom salário em valores entre quatro mil e dez mil reais. Uma segunda referência para a definição de bom salário é o valor de vinte mil reais, percebido como típico das principais carreiras jurídicas do setor público. O salário de vinte mil reais é principalmente definido como uma meta. Há também o uso da mensalidade do curso de Direito como referência para o salário que deveria ser recebido pelos advogados.

Virgínio afirma que a renda domiciliar necessária para que ele e a esposa tenham "estabilidade" é dez mil. No futuro, ele espera receber 20 mil reais mensais por ser essa a remuneração do delegado de polícia. Vinte mil reais, na percepção da grande maioria dos entrevistados, é um valor acima do necessário para suprir demandas de conforto. Porém, é um valor desejável por ser esse o salário das ocupações que almejam.

Hoje em dia, teria que ser perto de uns dez mil reais, nós dois (ele e a esposa), pra poder comprar coisas pra dentro de casa. Fora as contas do dia a dia, né?: água, luz, internet, comida, roupa, uma boa alimentação, manutenção do carro, coisas, gasolina, ração pro cachorro e pra tu poder ter um lazer de sair, poder passear, teria que ser mais ou menos isso. Porque hoje pra tu ter uma noção, eu e ela, dá mais ou menos quatro mil reais. Então, sobra nada. A gente não tem lazer, assim, sabe?, de vamo sair. A gente combina, a gente estuda e a gente vê tudo direitinho antes de sair, entendeu? Vamo no cinema? Vamo. O que tem de pagar de conta? Fazemos as contas. Então, podemo ir? Podemo. Tem dinheiro pra pagar. É mais ou menos por aí. Isso não é saudável, entende? Não acho saudável.

Olha, eu quero ser delegado, né? Um delegado ganha uns vinte mil por mês. É isso daí que eu espero um dia ganhar. Mas o que hoje a gente tá, o que hoje eu almejo é ter uma estabilidade, que seria ganhar isso daí: cinco mil pra cima, cada um, pra poder viver legal, viver bem.

Virgínio, 25 anos, advogado associado

A maioria dos entrevistados espera não ser possível atingir uma remuneração adequada para levar uma vida confortável na posição de advogado associado, mesmo com mais anos de experiência. Os recém-diplomados em Direito adaptam-se a essa situação no mercado de trabalho buscando ocupações que atendam aos requisitos de suas demandas de boa vida. A principal resposta às 
desigualdades no mercado de trabalho é elaborar estratégias de vida para a colocação profissional nas poucas posições de alto valor.

Uma boa vida também requer boas condições de trabalho. Para os entrevistados, um bom trabalho é aquele que provê renda adequada, contrato por CLT ou estatutário, benefícios trabalhistas, estabilidade, não realização de hora extra, remuneração de hora extra quando necessária, boas relações com o chefe e com os colegas, autonomia em definir horários e atividades, aprendizado constante, utilidade social, baixo nível de repetição das tarefas e baixo nível de subordinação ao trabalho dos superiores. Por exemplo, Felícia trabalha como técnica em eletrônica em uma empresa pública há seis anos, tendo todos os benefícios de uma servidora pública. Ao avaliar a ocupação atual, ela afirma que o aprendizado constante na área de formação superior, a interação com os colegas e superiores, a remuneração e o nível de repetição das tarefas são critérios relevantes para que ela tenha um bom emprego.

A primeira questão que o trabalho me deixa insatisfeita são as não oportunidades de aprendizado que ele me traz. Por exemplo, se eu tiver trabalhando num escritório, cada processo que cair na minha mão é oportunidade de aprendizado. Vai trazer uma coisa pra mim que ou eu não sei ou vai reforçar uma coisa que eu sei. No trabalho hoje, isso não acontece. As coisas que são trazidas pra mim são uma oportunidade de aprendizado, mas é um aprendizado que eu não quero mais. Então, tipo assim, é interessante, é legal o sistema elétrico. É muito interessante. Só que esse tempo que eu tô consumindo aprendendo sobre o sistema elétrico é o tempo que eu poderia tá consumindo aprendendo sobre o direito. Então, uma das coisas que incomoda muito no meu trabalho são as não oportunidades de aprendizado do mundo jurídico que ele me traz. A segunda questão são as pessoas com quem eu trabalho. São pessoas muito legais, competentes na área elétrica. Não na área jurídica. Eu não consigo no meu local de trabalho discussões sobre temáticas que são importantes pra minha formação profissional. As pessoas, nenhuma delas trabalhou com isso. A terceira questão são as atividades, né? Algumas das atividades que eu faço são ainda nesse conceito de linha de produção, sabe? De copiar e colar, de ficar fazendo tarefas repetitivas, rotineiras, assim, que não combinam com o meu perfil. A quarta questão é a questão financeira. Eu gostaria de ter uma remuneração condizente. Quando tu te forma numa faculdade, faz um mestrado, teu plano, tua ideia, além de ganhar conhecimento é financeiramente ter um retorno. Onde eu trabalho hoje, não tem nenhum tipo de retorno. É mais ou menos isso. 
As aspirações profissionais e a classificação ocupacional resultam, em parte, das definições de boa vida. As demandas de conforto são altas, uma vez que a renda necessária está acima da que a maioria dos entrevistados e dos seus pais recebem. Definições de boa vida com bases religiosas, bem como centradas em valores políticos anti-establishment ou no convívio social, pouco apareceram. Definições em que o conforto e as características das ocupações são centrais aumentam os efeitos negativos da desigualdade, pois implicam uma disputa social por bens semelhantes e monopolizados pelas classes superiores.

\section{Comparação com os familiares}

Foi pedido para que os entrevistados comparassem a experiência de vida deles com os pais, focando principalmente na experiência com a pessoa do mesmo sexo. Como desigualdade social é um fenômeno relacional, as pesquisas têm investigado os grupos de referência com os quais os atores comparam as suas experiências de vida (Irwin, 2015; Bottero, 2012; Sachweh, 2012). Bottero (2012) mostra que a maioria das pessoas considera, pelo menos do ponto de vista material, a sua vida melhor do que a de seus pais ou avós.

Muitos entrevistados das classes populares afirmaram que nunca compararam, antes da entrevista, a experiência deles com a dos pais. Disseram que eles e os pais viveram em épocas muito diferentes. Segundo os entrevistados das classes mais baixas, os pais não tiveram a oportunidade de terminar o ensino superior por fatores estruturais, começaram a trabalhar mais cedo e também se casaram mais cedo.

Quanto mais baixa a posição social, mais negativamente avaliada foi a experiência de vida dos pais e mais positivamente avaliadas são as mudanças sociais. Felícia, por exemplo, narra a experiência de vida da mãe como exemplo de uma vida que a entrevistada não gostaria de levar. Para ela, a expansão universitária promovida pelos programas governamentais da década de 2000 possibilitou que evitasse o destino social de vender sapatos na cidade onde reside sua mãe. A obtenção do emprego atual dela não dependeu do diploma de ensino superior, o que revela que esse discurso é reproduzido até mesmo por quem não transformou o título de nível superior em vantagens no mercado de trabalho.

Quando a minha mãe tinha a minha idade, 27 anos, eu tinha um ano. Então, ela tava morando no emprego. Ela trabalhava. Cuidava de três crianças e limpava casa. Ela era babá e empregada. Acho que ela devia tá bem desesperada. Ela tinha uma criança pra criar sozinha. Tava, sei lá, ganhando um salário mínimo (...). Eu acho que seria bastante difícil (levar a vida que a 
minha mãe levava). Não é uma vida que eu gostaria de ter tido. Até porque eu gosto muito de estudar e minha mãe não teve essa oportunidade. (...) Se eu não tivesse feito faculdade, eu provavelmente taria vendendo sapato lá na cidade onde minha mãe mora, né? É o que os meus colegas de ensino fundamental fazem. A grande maioria trabalha no comércio.

Felícia, 27 anos, classe urbana precária

Existe uma grande diferença de gênero nas respostas deste bloco de perguntas. As entrevistadas avaliaram negativamente a vida da mãe delas, afirmando que as últimas não tiveram independência financeira, foram mães muito novas e tiveram baixas aspirações profissionais. A avaliação da vida dos pais pelos entrevistados foi mais positiva.

Embora muitos entrevistados não estejam em uma situação muito diferente da de seus pais em termos salariais e contratuais, e em muitos casos vivenciam uma situação até inferior, a maioria considera que teve mobilidade social em comparação aos seus pais devido ao prestígio mais elevado das profissões jurídicas e à posse do diploma de ensino superior. Escolarização e prestígio ocupacional têm um peso maior para os entrevistados do que renda e forma de contrato para a definição de mobilidade social. Quando comparam as suas experiências com as dos irmãos que não completaram o ensino superior, afirmam estar em uma situação melhor, mesmo quando os irmãos têm um salário melhor. Porém, os entrevistados enaltecem a habilidade dos irmãos de terem adquirido carro e imóvel mais cedo do que eles. Por exemplo, o pai de Gregório trabalha há 18 anos como eletricista. Um dos seus irmãos trabalha como mecânico, recebendo um salário maior do que o dele. Ele afirma preferir estar na situação atual dele pelas "piores" condições de trabalho dessas ocupações e pelo status das ocupações jurídicas.

Eu acho que ponto negativo, pra mim, de ser eletricista é o perigo. Em primeiro lugar, o perigo. Sem sombra de dúvida. Em segundo lugar, de repente, não é uma profissão que eu me sentiria tão bem na questão de... Sei lá se pode dizer status social. Não que eu seja, assim, orgulhoso e eu quero, mas me sinto melhor no meio do Direito, sabe? Acho que tu é mais respeitado.

Gregório, 24 anos, classe intermediária

A classe média e a classe entre média e intermediária tendem a perceber a experiência de vida dos pais e o contexto em que os pais viveram de maneira positiva. São percebidas menos diferenças entre o contexto atual e o contexto em que seus pais viveram quando tinham a idade dos entrevistados. Para eles, a 
situação do país tem piorado. Ingressar nas ocupações mais altas era, segundo eles, menos competitivo.

O meu pai já tinha uma espécie de expectativa de crescimento maior e num período menor de poder escalar, subir a escala, em pouco tempo. Eu já não tenho essa expectativa. Eu já tenho... Acredito que a realidade nossa hoje é um pouco mais difícil. A gente tem milhares de advogados.

Cândido, 25 anos, classe média de origem

Bah, eu acho que a época dele (do meu pai)... Eu já refleti isso com um amigo meu de colégio. Eu acho que a época dessa geração dos nossos pais aí, de quem nasceu nos anos 50 a 70, é uma geração que pegou um período econômico, do capitalismo, um pouco mais, vamo dizer, assim, pra classe média era melhor. Mas acho que era muito pior pra quem era pobre.

Dionísio, 27 anos, classe média de origem

Qualificação e posição no mercado de trabalho são critérios que os entrevistados utilizam para avaliar a experiência de vida dos seus pais em comparação à deles. As entrevistadas, especialmente, ao comparar a experiência delas com a das mães, também consideraram a independência (com relação ao marido e aos pais) e o caráter, no sentido de atribuir mais valor às experiências no mercado de trabalho e valorizar o cuidado menos do que suas mães. Os pais são um dos grupos de referência utilizado para definir a posição social, tendo sido relevante principalmente para os entrevistados da classe média de origem. A percepção entre as classes populares de que o contexto social mudou reduz a relevância dessa referência para a avaliação de suas experiências de vida. A posição dos entrevistados no campo jurídico e segundo os parâmetros da subjetividade neoliberal constituem outros sistemas de valor significativos. A comparação social, fonte de sentimentos de desigualdade, assume várias referências.

\section{Conclusão}

Diferentemente de seus pais, os entrevistados das classes populares concluíram o ensino superior, possuindo, assim, uma credencial que possibilita acessar as ocupações de alto status socioeconômico. Contudo, em um contexto de expansão universitária, a probabilidade de alcançar essas ocupações é reduzida. No mapa mental dos entrevistados, as carreiras públicas e a docência universitária estão no topo da hierarquia ocupacional, constituindo objetivos a serem alcançados. Os empregos nos escritórios de advocacia são percebidos como melhores do que as ocupações que não requerem ensino superior, mas 
consideravelmente inferiores às carreiras públicas. Apesar de a maioria dos entrevistados considerar que a posição no mercado de trabalho deles é melhor do que a dos pais, essa não é a principal referência de avaliação da situação atual. A diferença nas condições de emprego entre as carreiras públicas e o emprego nos escritórios de advocacia e a definição de boa vida centrada no conforto material são referências que tendem a gerar avaliações negativas a respeito da situação no mercado de trabalho e a motivar a busca pela aprovação nos concursos públicos, mesmo em cargos que exigem somente nível médio.

A desigualdade social brasileira tem efeitos sobre aspectos subjetivos, como satisfação com a vida, percepções de sucesso ou fracasso e sentimentos de realização. O elevado retorno social de algumas ocupações em termos de benefícios empregatícios, respeito e salário em comparação com a maior parte destas que oferecem tais vantagens em um nível muito inferior é fonte de sentimentos e percepções negativos, que nem sempre são interpretados em uma lógica de desigualdade e injustiça social, na perspectiva dos entrevistados. A maioria dos entrevistados naturaliza as vantagens das ocupações do setor público. Não se questionam, por exemplo, sobre o valor de vinte mil reais recebido por muitas carreiras do Judiciário no estado da pesquisa.

Conforme colocam, principalmente, Lamont (2000; 2012), Sayer (2005a; 2005b) e Skeggs (1997; 2004), os atores sociais são capazes de responder às bases de respeito dominantes por meio de heterarquias. Apesar de posição no mercado de trabalho, qualificação e consumo serem as bases dominantes de respeito por apreciação no momento atual do capitalismo global, os membros das classes inferiores são capazes de elaborar bases alternativas, por exemplo, por meio do cuidado, da religião, dos ideais de hipermasculinidade e da negação do sistema capitalista. Neste caso, as bases predominantes prevaleceram. Os ideais de crescer economicamente, levar uma vida "confortável” e ingressar nas ocupações socialmente mais valorizadas geram estratégias de vida e formam referências para a avaliação da situação atual.

Os dados deste artigo assemelham-se às evidências das pesquisas com alunos de graduação. No entanto, existem diferenças marcantes entre a abordagem realizada nesta pesquisa e a abordagem predominante entre os demais autores brasileiros. Muitas pesquisas (por exemplo, Castro, 2014; Mongim, 2016; Casali; Mattos, 2015; Oliveira; Bock, 2016; Neves, Faro; Schmitz, 2016) usam as categorias estatais de prounistas e cotistas como indicadores de classe social. Analisam os dados, muitas vezes, em uma perspectiva de avaliação de políticas públicas, utilizando o ingresso de jovens das classes populares no ensino superior como critério de sucesso das políticas analisadas. Os valores dos entrevistados são 
interpretados, principalmente, em uma perspectiva de aumento das oportunidades de vida promovido pelo ensino superior. Nesta pesquisa, a referência analítica foram as desigualdades no mercado de trabalho. Houve um debate mais próximo com a literatura da estratificação de classe, ao ter optado pela categoria classe social (em vez de prounista ou cotista) e ter tratado da classificação ocupacional. Teoricamente, a variedade de abordagens contribui para o enriquecimento da compreensão do problema.

Uma sociedade de sucesso provê aos seus membros recursos para uma vida significativa. Quando a maioria da população busca os mesmos bens, e existe a percepção de que os bens valorizados são muito melhores do que os outros bens, torna-se mais difícil alcançar esse ideal. A renda recebida por boa parte dos entrevistados e por seus pais está acima da mediana salarial dos trabalhadores brasileiros. Nenhum deles tem as necessidades mais básicas comprometidas. Porém, existe a motivação de escalar a escada social. Melhorar de vida. Alcançar melhores posições sociais. $\mathrm{O}$ fato de existir ocupações que proporcionam rendas muito superiores às que possuem, com condições de emprego mais favoráveis, geram consequências pessoais negativas devido à posição social, apesar de muitos já estarem acima da mediana nacional. Os sentimentos relacionados à desigualdade social - revelados pela má avaliação da posição atual no mercado de trabalho e pela vontade de mudar a situação ingressando no setor público -, neste caso, resultam de esquemas baseados na tríade consumo, sucesso profissional e qualificação e na desigualdade social entre o topo e todo o resto.

\section{Referências:}

A TRIBUNA. Pesquisa aponta cursos que mais formam no país. Disponível em: <http:// www.atribuna.com.br/noticias/noticias-detalhe/cidades/pesquisa-aponta-cursos-que-mais-formam-no-pais/?cHash=5653d14a057a547a8e 4db4e7103731db $>$. Acesso em: 11 set. 2019.

BAKER, David P. Minds, Politics, and Gods in the Schooled Society: Consequences of the Education Revolution. Comparative Education Review, v. 58, n. 1, 2014, pp. 6-23.

BALL, Stephen. Subjectivity as a site of struggle: refusing neoliberalism? British Journal of Sociology of Education, v. 37, 2016, pp. 1129-1146.

BOTTERO, Wendy. Who do you think they were? How family historians make sense of social position and inequality in the past. British Journal of Sociology, v. 63, n. 1, 2012, pp. 54-74.

BOURDIEU, Pierre. A distinção: crítica social do julgamento. Porto Alegre, Zouk, $2007(560)$. 
CASALI, Alípio Márcio Dias; MATTOS, Maria José Viana Marinho de. Análise de estudos e pesquisas sobre o sentido social do programa Universidade para Todos (PROUNI). Ensaio: avaliações e políticas públicas em educação, Rio de Janeiro, v. 23 , n. 88,2015 , pp. $681-716$.

CASTRO, Guilherme Caldas. A nova classe média brasileira: necessidades, anseios e valores: um estudo da mobilidade social, a partir dos universitários da UERJ. Tese de doutorado, Rio de Janeiro: UERJ, 2014.

CNJ - Conselho Nacional de Justiça. Censo do Poder Judiciário. Brasília, 2014. Disponível em: <http://www.cnj.jus.br/images/dpj/CensoJudiciario.final.pdf>. Acesso em: 11 set. 2019.

COLLINS, Randall. The credential society: an historical sociology of education and stratification. Orlando, Academic Press, 1979 (222).

DARWALL, Stephen. Two kinds of respect. Ethics, v. 88, n. 1, 1977, pp. 36-49.

DI STASIO, Valentina. Who is ahead in the labor queue? Institutions' and employers' perspective on overeducation, undereducation, and horizontal mismatches. Sociology of Education, v. 90, n. 2, 2017, pp. 109-126.

ELIAS, Peter; PURCELL, Kate. Is mass higher education working? Evidence from the labour market experiences of recent graduates. National Institute Economic Review, v. 190, n. 1, 2004, pp. 60-74.

EVANS, Peter; WILLIAM, Sewell. The neoliberal era: Ideology, policy, and social effects. In: Social Resilience In The Neoliberal Era, editado por Peter A Hall and Michèle Lamont. Cambridge, Cambridge University Press, 2013.

FIGUEIREDO, Hugo; BISCAIA, Ricardo; ROCHA, Vera; TEIXEIRA, Pedro. Should we start worrying? Mass higher education, skill demand and the increasingly complex landscape of young graduates' employment. Studies in Higher Education, v. 42, n. 8, 2017, pp. 1401-1420.

FLEMMEN, Magne Paalgarde; TOFT, Maren; ANDERSEN, Patrick Lie; HANSEN, Marianne Nordli; LJUNGREN, Jorn. Forms of Capital and Modes of Closure in Upper Class Reproduction. Sociology, v. 51, n. 6, 2017, pp. 1277-1298.

FRANCOMBE-WEBB, Jessica; SILK, Michael. Young girls' embodied experiences of femininity and social class. Sociology, v. 50, n. 4, 2016, pp. 652-672.

IBGE. Apresentação do censo da educação superior. Disponível em: <https://abmes.org. br/arquivos/documentos/apresentacao_censo_educacao_superior.pdf $>$. Acesso em: 11 set. 2019.

IRWIN, Sarah. Class and comparison: Subjective social location and lay experiences of constraint and mobility. The British Journal of Sociology, v. 66, n. 2, 2015, pp. 259-281. JUNIOR, Edmundo Lima de Arruda. Bacharéis em Direito e crise de mercado de trabalho: Algumas reflexões. Seqüência: Estudos Jurídicos e Políticos, v. 4, n. 6, 1983, pp. 29-40. 
LAMONT, Michèle; HALL, Peter. Introduction. In: LAMONT, Michèle; HALL, Peter. (Ed.) Social resilience in the neoliberal era. Cambridge: Cambridge University Press, 2013.

LAMONT, Michèle; MOLNÁR, Virág. The study of boundaries in the social sciences. Annual Review of Sociology, v. 28, 2002, pp. 167-195.

LAMONT, Michèle. Toward a comparative sociology of valuation and evaluation. Annual Review of Sociology, v. 38, 2012, pp. 201-221.

The dignity of working men: Morality and the boundaries of race, class, and immigration. New York, NY: Russell Sage Foundation, 2000.

LEMOS, Ana Heloisa da Costa; DUBEUX, Veranise Jacubowski Correia; PINTO, Mario Couto Soares. Educação, empregabilidade e mobilidade social: convergências e divergências. Cadernos EBAPE.BR, v. 7, n. 2, 2009, pp. 368-384.

LIMA, Aline Virginya de Queiroz. Estou formado(a), e agora? Uma análise sobre o sofrimento psíquico de desempregados recém-formados de Instituições de nível superior de São Luís-MA. Apresentação em evento, IV Jornada Internacional de Políticas Públicas, 2010.

MACIENTE, Aguinaldo Nogueira; NASCIMENTO, Paulo Andrade Meyer M.; SERVO, Luciana Mendes Santos; VIEIRA, Roberta da Silva; SILVA, Carolina Andrade. A inserção de recém-graduados em engenharias, medicina e licenciaturas no mercado de trabalho formal. Radar, v. 38, 2015, pp. 7-22.

MCKENZIE, Jordan. Happiness Vs Contentment? A Case for a Sociology of the Good Life. Journal for the theory of social behavior, v. 46, n. 3, 2016, pp. 252-267.

MEDEIROS, Marcelo. O que faz os Ricos ricos: um estudo sobre fatores que determinam a riqueza. Tese de doutorado, Brasília: UnB, 2003.

MEDEIROS, Marcelo; SOUZA, Pedro H. G. Ferreira de; CASTRO, Fábio Avila de. O Topo da Distribuição de Renda no Brasil: Primeiras Estimativas com Dados Tributários e Comparação com Pesquisas Domiciliares (2006-2012). Dados, Rio de Janeiro, v. 58, n. 1, 2015, pp. 7-36.

MONGIM, Andrea Bayerl. Itinerários de escolarização e mediações subjacentes: a experiência de discentes beneficiários do Prouni. Ensaio: avaliações e políticas públicas em educação, Rio de Janeiro, v. 24, n. 93, 2016, pp. 804-823.

NEVES, Paulo Sérgio da Costa; FARO, André; SCHMITZ, Heike. As ações afirmativas na Universidade Federal de Sergipe e o reconhecimento social: a face oculta das avaliações. Ensaio: Avaliação e Políticas Públicas em Educação, v. 24, n. 90, 2016, pp. $127-160$.

OECD. Education at a glance 2016: OECD indicators. OECD Publishing, Paris, 2016.

OLIVEIRA, Alessandra dos Santos; BOCK, Ana Mercês Bahia. Escolha do curso por prounistas: estudando a dimensão subjetiva da desigualdade. Psicologia Escolar e Educacional, v. 20, n. 2, 2016, pp. 303-312. 
PAYNE, Geoff; GREW, Clare. Unpacking 'class ambivalence' some conceptual and methodological issues in accessing class cultures. Sociology, v. 39, n. 5, 2005, pp. 873-891.

RIDGEWAY, Cecilia. Why status matters for inequality. Annual review of sociology, v. 79, n. 1, 2013, pp. 1-16.

RUGGERA, Lucia; BARONE, Carlo. Social closure, micro-class immobility and the intergenerational reproduction of the upper class: a comparative study. British Journal of Sociology, v. 68, n. 2, 2017, pp. 194-214.

SACHWEH, Patrick. The moral economy of inequality: Popular views on income differentiation, poverty and wealth. Socio-economic Review, v. 10, n. 3, 2012, pp. 419-445.

SATYBALDIEVA, Elmira. Working class subjectivities and neoliberalisation in Kyrgyzstan: developing alternative moral selves. International Journal of Politics, Culture and Society, v. 13, n. 1, 2018, pp. 31-47.

SAYER, Andrew. The moral significance of class. Cambridge, Cambridge University Press, 2005a.

Class, moral worth and recognition. Sociology, v. 39, n. 5, 2005b, pp. 947-963.

SEMESP. SEMESP apresenta dados de empregabilidade no ensino superior. Disponível em: <http://www.semesp.org.br/site/noticias/semesp-apresenta-dados-de-empregabilidade-de-formados-no-ensino-superior/>. Acesso em: 11 set. 2019.

SEN, Amartya. Desenvolvimento como liberdade. São Paulo, Companhia das Letras, 2000, (409).

SENNETT, Richard; COBB, Jonathan. The hidden injuries of class. New York, W.W. Norton \& Company, 1972 (288).

SENNETT, Richard. Respeito: a formação do caráter em um mundo desigual. Rio de Janeiro, Record, 2004 (336).

SILVA, Mariléia Maria da. Redes de relações sociais e acesso ao emprego entre os jovens: o discurso da meritocracia em questão. Educação e Sociedade, v. 31, n. 110, 2010, pp. 243-260.

SIMONSEN, Ricardo; GONZALEZ, Sidnei. OAB em números. v. II. Brasília, 2014.

OAB em números. Vol. III. Brasília, 2016.

SKEGGS, Beverley. Formations of class and gender: becoming respectable. London, Sage, 1997 (200).

. Class, self and culture. London, Routledge, 2004 (226).

The making of class and gender through visualizing moral subject formation. Sociology, v. 39, n. 5, 2005.

Values beyond value? Is anything beyond the logic of capital? British Journal of Sociology, v. 65, n. 1, 2014, pp. 1-20.

SOUZA, Jessé. A Ralé Brasileira: Quem é e como vive? Belo Horizonte: Editora UFMG, $2009(512)$. 
Os Batalhadores Brasileiros: nova classe média ou nova classe trabalhadora? Belo Horizonte: Editora UFMG, 2010 (354).

STUBER, Jenny. Talk of Class: The discursive repertoires of white working- and upper-middle-class college students. Journal of Contemporry Ethnography, v. 35, n. 3, 2006, pp. $285-318$.

THOLEN, Gerbrand. Graduate work: Skills, credentials, careers, and labour markets. Nova Iorque: Oxford University Press, 2017a.

Symbolic closure: Towards a renewed sociological perspective on the relationship between higher education, credentials and the graduate labour market. Sociology, v. 51, n. 5, 2017b, pp. 1067-1083.

. The changing opportunities of professionalization for graduate occupations. Comparative Sociology, v. 16, n. 5, 2017c, pp. 631-633.

WILLIS, Paul. Aprendendo a ser trabalhador: Escola, Resistência e Reprodução Social. Porto Alegre: Artes Médicas, 1991 (241).

Recebido em: 30/05/2018

Aprovado em: 04/07/2019

\section{Como citar este artigo:}

PEREIRA, Ricardo Bernardes. As dimensões morais de classe social: Avaliações do mercado de trabalho e das experiências de vida de recém-diplomados em Direito. Contemporânea - Revista de Sociologia da UFSCar, v. 9, n. 3, set.- dez. 2019, pp. 917-942. 